\title{
M.Ö. 8. BİNDE ANADOLU VE KIBRIS İLİŞKILLERİ: AKANTHOU*/TATLISU KURTARMA KAZISI
}

\author{
Müge ŞEVKETOĞLU
}

\begin{abstract}
Anathtar Kelimeler: Kibris, Anadolu, Akeramik, Neolitik, Obsidyen
\end{abstract}
Keywords: Cyprus, Anatolia, Aceramic, Neolithic, Obsidian

\begin{abstract}
Özet
Kıbrıs prehistoryası son 10 yıl içerisinde büyük araştırma ve sonuçlara şahit olmuştur. Özellikle 1930'lu yılların düşünce ve teorileri, yapılan yeni kazılar 1şığında çürütülmüştür. Kıbrıs - Anadolu ilişkilerinin varlığına 'çok zayıf bir ihtimal' olarak bakılan yıllar gerilerde kalmıştır. Bu değişimde önemli rol oynayan iki yerleşim yeri Parekklisha-Sbillourokambos ve Akanthou-Arkosyko/TatlisuCiftlikedüzü dür (Res. 1). Her iki yerleşim alanında da başka yerlerde görülmeyen ve Akeramik dönemin erken safhasını temsil eden sığır kemikleri, pikrolit taşından kazıma desenli jetonlar (Res. 2) ve en önemlisi Anadolu kökenli obsidyen buluntular ele geçmiştir. Akanthou/Tatlısu'nun Kıbrıs'nn kuzey kıyı şeridinde yer alması ve Kıbrıs'taki aynı dönem yerleşmeleri arasında en fazla obsidyen buluntusuna sahip olması, Kıbrıs - Anadolu ilişkilerini göz ardı edilemeyecek bir şekilde kanıtlamaktadir.
\end{abstract}

Kıbrıs'taki Prehistorya Araştırmalarının Tarihine Kısa bir Bakış

1927-1931 y1llar1 arasında isimlerini 'İsveç Arkeoloji Seyranı' olarak belirleyen ekibin başkanı olarak Einar Gjerstad, Yunan Medeniyeti ile başlatılan Kıbrıs tarihinin bu zamandan çok öncelere, Neolitik dönemlere dayandığını ispatlayan ilk çalışmaları gerçekleştirir. İsveçlilerin adanın birçok yerinde gerçekleştirdikleri ve mihenk taşı niteliğindeki ilk bilimsel çalışmalar çerçevesinde açı̆̆a çıkarılan Vouni sarayı hazinesi, Ayia Irini tapınağında bulunan pişmiş topraktan yapılmış büyüklü küçüklü insan ve hayvan heykelleri, Idalion kazıları, Enkomi Geç Tunç Çağı mezarları, Nitovikla kalesi ve Lapta Tunç Çağı mezarları isim yapmış önemli buluntu yerleri ve buluntu gruplarına birkaç örnektir. Neolitik Dönem'in en önemli iki kazısını da gerçekleştiren İsveçliler, ayrıca Kıbrıs'ta Neolitik Döneme ait ilk kazı çalışmalarını gerçekleştiren kişiler olarak Kıbrıs arkeoloji tarihine girmiştir. $\mathrm{Bu}$ önemli kazıların biri, Güzelyurt körfezinin batı ucunda yer alan, kıyıdan 100 metre uzaklıkta 150 metre uzunluğunda, 30 metre genişliğinde ve 50 metre yüksekliğinde bir adacik olan Petra tou Limniti ya 
da 'Türkçe adıyla Limnidi Kayalı̆̆ı'dır. Bu adacık Vouni sarayından rahatlıkla görüldügünden, sarayın kazıları esnasında İsveç ekibinin dikkatini çekmiştir ${ }^{1}$. Bir pazar günü, kiraladıkları teknenin gelmemesi üzerine adaya yüzerek ulaşan ekip, $\mathrm{Ne}$ olitik yerleşim yerini keşfeder. Gjerstad, kendi anlatımı ile fareler ve neolitik tozla savaş ederek iki haftada Petra tou Limniti kazısını bitirir ve Vouni sarayının uygarlığina döner.

"After two weeks of digging during which we fought against rats and Stone Age dust the work on Petra tou Limniti was finished. Alfiros put on a clean, white shirt. Lazaros sounded his shell for the last time and once again attached his whistle to his watch chain. We left Petra tou Limniti, pioneers in a prehistoric wilderness, and returned to the palatial civilisation of Vouni." ${ }^{2}$

Einar Gjerstad, Ages and Days adlı Kitabinda (1980), Petra tou Limniti kazısı ile ilgili bölümün başlığını 'Adanın uyanışı' olarak isimlendirmiştir. Ancak bu kazı sadece adanın uyanışı değil ayrıca gizli kalmış Neolitik ve Kıbrıs prehistoryasının da uyanışı olmuştur. İsveç Arkeoloji Seyranı başlamadan önce Einar Gjerstad'ın 1924 yılında kazdığı Neolitik yerleşim yeri, Mağusa şehrinin $10 \mathrm{~km}$ güney batısına düşen Frenaros- Vounastiridir'. Gjerstad, Petra tou Limniti ve Frenaros'un buluntularına ve her iki yerde seramik olmaylşına değinerek bu iki yerleşimi Neolitik

* İlk kayıtlarında bulunduğu köy olan Akanthou ismi ile geçmesi ve yabancı yayınlarda sadece bu isimle bahsedilmesinden dolayı, karıșıklık yaratmamak için aynı isim kullanılmış, yanında ise köyün Türkçe ismi olan Tatlısu verilmiștir. 1974 öncesi Akanthou isimli bu köy, bugün güney Kıbrıs sinırları içinde kalan Tatlısu köyü göçmenlerinin yerleştirilmesi ile köyün ismi değiștirilmiştir.

Gjerstad 1980, 16.

2 Gjerstad 1980, 23-24.

3 Frenaros ayrıca Phenaros olarak da yazılmaktadır.
Döneme tarihler ${ }^{4}$. Bu iki yerleşim yeri arasında tespit ettiği tek farklılık, evlerin duvarlarının aynı malzeme ve aynı teknikle yapılmasina rağmen FrenarosVounastirinnin duvarlarının daha düz ve uzun, köşelerinin ise daha dik aç1l oldugudur ${ }^{5}$.

İsveç Ekibi, kazılarının sonunda Kıbr1s üzerine yazılan ilk bilimsel yayınları yapar. 12 ciltlik bu çalışmada ilk kez Neolitik Dönem'den Roma Dönemi'ne kadar bir kronolojik tablo da çizilmiş olur. Günümüzün standartlarını yansıtan fotoğraflar ve çizimlerle Kibrıs arkeolojisinin de sağlam temeller üzerinde oluşmasına yardımcı olan bu yayınlar günümüzde Kıbrıs arkeolojisinin İncili olarak anılmakta ve güncelleştirilmemesine rağmen halen atıfta bulunularak önemlerini korumaktadır. Kıbrıs'ta çalışan diğer arkeologlara Yunan medeniyetlerinden önce Neolitik Çă̆ insanlarının adaya yerleştiğini ve bunların Anadolu'dan gelmiş olabileceğini açıklayan Gjerstad böylelikle Kıbrıs Neolitik Dönemi üzerine çalışmaların başlamasına da öncülük etmiş önemli bir bilim adamıdir.

Gjerstad'in öncü çalışmalarından sonra Kıbrıs Neolitiğine başka bir boyut kazandıran bir diğer arkeolog ise Fransa'da eğitim görmüss Porphyrios Dikaios'tur. Ünlü Khirokitia yerleşim yerinin kâşifi ve kazı başkanı olan Dikaios, buradaki çalışmalarıyla Kıbrıs arkeoloji tarihinin Akeramik Neolitik Dönem'ine is-

Gjerstad 1980, 22.

5 Son arkeolojik araştırmalarda yuvarlak evlerin bir önceki safhasında köşegen evlerin varlığ1, (TatlısuCiftlikedüzü) Frenaros'un yeniden incelenmesinin gerekliliğini ve Neolitik çağın erken safhalarında bu gibi mimari kalıntıların mevcudiyeti olasılığına işaret etmektedir. Araştırmalar ilerledikçe yuvarlak evlerin Kıbrıs'ın ilk mimari özelliği olmadığı ortaya çıkacaktır. 
mini yazdırır ve bu dönemin, yerleşim yeri Khirokitia'nın adını alan bir kültür olarak anılmasını kazandıran kişi olur. Khirokitia kültürünün Yakın Doğu'dan gelmiş olabileceğini ve hatta ev damlar1nin tholos damlarina benzer şekilleriyle Tepe Gawra, Tell Halaf, Arpachiyah, Jericho, Byblos gibi farklı dönemlere ait yerleşimlerin mimari geleneklerini yansıttığını savunur 6 .

1924 ve 1936 yıllarında yapılan Neolitik Dönem çalışmaları (Kalkolitik Dönemler üzerinde de çalışılmıştır ancak konumuz gereği bu makalede sadece Neolitik Döneme yer verilmektedir) bilgiler değişime uğramadan 1990'lı yıllara kadar gelmiştir. Kibrı'ın güneyine düşen Parekklisha-Sbillourokambos ve Kibris'n kuzey kiyisinda yer alan AkanthouArkosykos ya da Tatlısu-Çiftlikdü̃ü çalışmaları, bu çăg ile ilgili çok önemli yeni bilgiler sunarak Kıbris kronolojisinin tekrar düzenlenmesini ve daha eskilere gitmesini sağlayan veriler ortaya koymuştur.

\section{Khirokitia M.Ö. 7000}

Önceleri M.Ö. 3700-3400'e ${ }^{7}$, daha sonra ise M.Ö. $7000^{8}$ yıllarına tarihlenen Khirokitia'da bulunan gelişmiş kültür, mimari tarz, evcilleştirilmiş hayvan kemikleri ve bitkiler ile bu dönemin gelişmiş taş aletleri, Khirokitia kültürünün ada d1şından, komşu ülkelerden birinden gelmiş olabileceğini düşündürmüştür? ${ }^{9}$. Khirokitia'da bulunan ve sayıları bir düzineyi geçmeyen Anadolu kaynaklı obsidyen aletlerin, Suriye - Filistin yoluyla Kibrıs'a

\footnotetext{
Dikaios 1953, 339.

Dikaios 1953, 341.

Le Brun 2001, 109.

Dikaios 1953, 339.
}

ulaşmış olabileceği varsayılıp doğrudan bir Anadolu-Kıbrıs bağlantısının varlığı uzun yllar kabul edilmemiştir. Khirokitia mimarisi Jericho mimarisine benzetilmiş ve Yakın Doğu'nun Akdeniz kıyıları Kıbrıs'ın ilk yerleşik insanlarının anavatanı olarak gösterilip günümüze kadar, yani tam 70 yll, bu yorum kabul görmüsstür. Anadolu ve Kıbrıs'ın kültürel farklılıkları tüm bu zaman boyunca bu varsayımın kanıtı olarak öne sürülmüştür. Ancak, Anadolu'yla bağdaşmayan farklılıklar her firsatta öne sürülmesine rağmen benzer bir durumun Yakın Doğu için de var olduğu pek fazla vurgulanmamıştır. Kıbr1s'ta Khirokitia öncesi bir dönemin geçen 70 y1l içinde bulunamaması, Khirokitia kültürünün yabancı bir kültür olduğunu ve Kıbrıs içerisinde gelişmiş, Kıbrıs'a has bir Neolitik kültür olamayacağını düşündürmüştür. Bu varsayım zaman içerisinde yapılan çalışmaların sayesinde değişikliğe uğramıştır. Kıbrıs'in zengin uygarlıkları, tapınakları, mezarları, hâlihazırda yüzeyde görülebilen zenginlikleri, özelikle Tunç Çağ1 ve sonrası medeniyetleri ile ilgili çalışmaların yoğunluğu ve ortaya koyduğu zenginlikler, taş eser üreten bu erken toplumların yerleşimlerine daha az ilgi gösterilmesine sebep olmuştur.

\section{Akrotiri-Aetokremnos (M.Ö. 9300)}

1980 yllında Alan Simmons başkanlığında ve National Geographic Society'nin katkılarıyla, adaya ulaşan ilk canlılar olan cüce fil ve cüce su aygırlarının kemiklerinin bulunduğu Akrotiri yarımadasında kazılara başlanmıştır. Kazılarda cüce su 
aygırlarına ait binlerce kemik $^{10}$ ve insan elinden çıkma birçok çakmaktaşı alet bulunmuştur ${ }^{11}$. Bu aletlerin daha sonraki dönemlerde bilinmemesi, avc1 ve toplayıc1 olan bu insanların M.Ö. 9000 ylllarında Kıbrıs'a gelip bu hantal hayvanları tükettikleri gibi kendilerinin de tükendiği veya geldikleri gibi geri döndükleri fikrinin ileri sürülmesine neden olmuştur. Aslında Akrotiri'de insan varlığının olup olmadığ tartışmaya açık olan bir konudur ve hâlâ daha birçok arkeolog tarafindan insan ve cüce hayvanların aynı dönemde yaşamış olup olmadikları sorgulanmaktadır. Akrotiri kazılarından çıan önemli bir diger sorun Akrotiri ve Khirokitia arasında bulunan 2000 y1llık kronolojik boşluktur ve bu dönemde neler olduğudur.

Kalavassos-Tenta (M.Ö. 7600) ve Parekklisha-Shillourokambos (M.Ö. 8200)

Son 15 yıldır yapılan çalışmalar (M.Ö. 8200'lere tarihlenen Kıbrıs'ın güney kı1larındaki Parekklisha-Shillourokambos yerleşiminin erken safhas1, Kalavassos-Tenta ve kuzey kıyısındaki Tatlisu-Ciftlikdüøü'ndeki kazı çalışmaları) bu sorgulanan boşluğu kapatacak buluntuları gün ışığına ç1karmıştır.

M.Ö. 8200 y1lina tarihlenen Shillourokambos'ta bulunan yarı evcilleştirilmiş domuz, keçi, koyun ve diğer hayvanlar, 400 adet'in üzerinde obsidyen aletler $^{12}$, Khirokitia kültürünün Kıbrıs içerisinde gelişmiş bir kültür olabileceği ve obsidyenin yüzlercesinin ancak doğrudan

10 Toplam $505+$ cüce suaygırına ait kemikler, bulunan tüm hayvan çeșitlerinin \%98.3 nü teșkil etmektedir (Simmons 1999, 157).

11 Simmons 1999, 137-151.

12 Guillaine 2003, 92.
Anadolu'dan gelebileceği konusunu tekrar gündeme getirmiştir. Yine bazı arkeologlar, yüzlerce obsidyeni yetersiz bir Anadolu bağlantısı olarak gösterip, Parekklisha'nın coğrafi konumunun Yakın Doğu'ya yakınlığını öne sürerek bu fikre karş1 durmuşlardır.

\section{Akanthou-Arkosyko/Tatlisu- Çiftlikdüzü (M.Ö. 8200) ${ }^{13}$}

Tatlısu-Ciftlikdü̃ü, Kıbris adasinın kuzey doğusunda, Girne ile Karpaz yar1madasının sinırında, denize hakim bir coğrafi konumdadir. Akanthou/ Tatlisu'nun $50 \mathrm{~km}$ kuzeyinde yer alan Anadolu kıyıları, havanın açık olduğu bir günde rahatlıkla görülebilmektedir. Akanthou/Tatlısu denizden 15 m yükseklikte olup, tatlı su kaynaklarına çok yakındır. Tam kuzeyinde bir pinar, doğu ve batısında ise günümüzde sadece yağmurlu kış aylarında akan dereler vardır. Hemen güneyinde ekilebilecek verimli topraklar ve daha güneyinde Bessparmak dağları ve ormanlar yer almaktadır.

Tatlısu-Ciftlikdürü, ilk kez 1931 y1lında Kıbrıs Müzesinin yaptığ yüzey yaraştırmaları sirasinda o zamanki ismi ile Akantho-Arkosykos olarak kayıtlara geçmiştir.

1996 yılında tarafımızdan gerçekleştirilen sistemli yüzey araştırmaları sırasında arkeolojik önemi anlaşılan Akanthou /Tatlısu'da, 1999 yılında Doğu Akdeniz Üniversitesi Arkeoloji Bölümü olarak arkeolojik çalışmalar başlatılmıştır ${ }^{14}$ (Res. 3).

\footnotetext{
132004 yilinda karbonlaşmış tohumların gönderildiği Oxford Radyokarbon labaratuarinda yapilan analizler sonucunda Akanthou/Tatlisu'nun ilk safhaları M.Ö. 8200'e tarihlenmiştir.

14 Şevketoğlu 2000, 75-79, 117.
} 
2003 Aralık ayında yaptığımız jeofizik çalışmalarında, yerleşimin 1996 yılı yüzey araştırmaları sonucunda tespit edilen büyüklükte olduğu, yani 140 metreye 280 metre boyutlarında bir alana yayıldığı ortaya çıkmıştır. Kıbrıs genelinde ilk kez bu kadar büyük bir bölgede ve başarllı sonuçlar veren jeofizik çalışmaları gerçekleştirilmiştir. Bir sonraki kazı hedefimizi de belirleyecek olan jeofizik çalışmalarında kullanılan direnç ölçme metodunun yanı sıra manyetik ölçüm çalışmaları yapilması planlanmıştır.

\section{Akanthou/Tatlisu Mimarisi}

Akanthou/Tatlısu'da şimdiye kadar toplam 6 farklı evin kazısı gerçekleştirilmiştir. Bu evler yaklaşık 5 metre çapında olup şekil itibarı ile kareye yakın veya daireseldir. Tüm evler çağdaş olmalarına rağmen farklı zamanlarda yapılmıştır. Tüm evlerin sıvalı zemini bulunmaktadır. Temeller taş ve kerpiçten olup üst duvarlar sadece kerpiçtir. İç ve diş duvarlar s1vanmış ve koyu kahverengi/kırmızı renklerde boyanmıştır. Evlerin bazılarında ocaklar ve firınlar vardır. Evlerin duvarlar1 birbirine yaslanmaktadir.

Mimari bilgilere 1ş1k tutan önemli başka bir gösterge ise dikmeler üzerine inşa edilmiş yapıların izleri olarak bulunan dikme delikleridir (Res. 4). Dikme delikleri Kıbrıs Erken Akeramik Dönemi'nin karakteristik özelliklerinden birisi olup, Tenta ve Shillourokambos gibi yerleşim yerlerinde de görülmektedir. Zemin, siva altında bulunan çakmaktaşı parçacıkları üzerine oturtulmuştur. Birçok siva katı olan zeminlerin belli aralıklarla yenilendiğini söylememiz mümkündür. Yıkılmış bir duvar ve kerpiç döküntü arasında sağ- lam bulduğumuz bir başka boyalı duvar kalıntısı, duvarların da sırası geldikçe tekrar sıvandığını ve boyandığını göstermektedir. Evlerin birinde bulunan oyulmuş taş içerisindeki boya kalıntıları ve kenarı rendelenmiş bir boya parçası bize boyama yöntemi hakkında ipuçları vermektedir.

\section{Sivalı Tekneler}

Evlerin içinde ve dışında olmak üzere toplam 7 adet sivalı tekne bulunmuştur (Res. 5, 6, 7). Tekneler yuvarlak veya oval ağızlı olup çapları $70 \mathrm{~cm}$, derinlikleri ise $50 \mathrm{~cm}$ kadar olabilmektedir. Teknelerin hemen hemen tümü yuvarlak taşlar ile doldurulmuştur. $\mathrm{Bu}$ taşların su 1sıtmak için kullanılabileceği düşünülmekle birlikte taşlarda herhangi bir yanık veya çatlama izi görülmemiştir. Bu tekneler, Kıbr1s'in diğer yerleşimlerinden bilinmemekte, Akanthou-Arkosykol Tatlisu-Ciftlikdüəü örnekleri bilinen en erken örnekleri teşkil etmektedir.

\section{Kireç veya Jipsten Sıva İmalatı}

Henüz analizi yapılmadığı için kimyasal bileşimin jips veya kireç olup olmadığ ile ilgili ayırım yapılamamıştır. Buna rağmen ilginçliğini yitirmeyen bu üretim teknolojisinden bahsetmek yerindedir.

Açmanın güneybatı kısmında yer yer sarı kahverengi renkte sıvalı bir çukur içerisinde yanık ve yüksek ateşten çatlamış bir çakmaktaşı yığını bulunmuştur. Bu çukurun kenarlarında $2.50 \mathrm{~m}$ aralıklarla 4 adet küçük, sığ ve dairesel çukur vardır. 40 ile $60 \mathrm{~cm}$ arasında çaplarda olan bu çukurlar içerisinde birkaç kat beyaz sıva veya kireç bulunmuştur. Özellikle çakmaktaşı çukurunun etrafina yerleştirilmiş olan bu çukurların yan yana dizilmiş sıva 
veya kireç yoğurma yerleri olabileceğini düşünmekteyiz. Büyük ve küçük çukurların yanı sıra $80 \mathrm{~cm}$ çapında yuvarlak ağızlı, düz kenarlı ve düz dipli 5 çukur daha tespit edilmiştir. Bu çukurların dolgusu açık gri renkte kat kat sıvalardan oluşmaktadır. Bir örnekte 11 kat siva bulunmuştur (Res. 8). Kuruyan siva her defasında çukur içerisinde bir kat daha oluşturarak çukuru doldurmuş ve işlevini yitirmesine neden olmuştur.

Üç değişik boyda ve kasıtll olarak düzenli yerleştirilmiş çukurların kerpiç, kireç veya sıva yapımı ile ilgili işlevlerinin olduğu düşünülmektedir. Benzeri yapılarla karşılaştırdığımız zaman Ürdün Ain Gazal ve İsrail Yiftahel'de ${ }^{15}$ ve diğer yerleşimlerde uygulanan Neolitik Dönem sıva üretim teknolojisiyle benzerlik göstermektedir. ${ }^{16}$ İsrail ve Ürdün'deki kazılarda bu tip çukurların toplum tarafindan ortak kullanılan kireç firınları ve sıva üretim alanları olduğu ileri sürülmektedir. Dış duvara ait bir sıva kalıntısı ise Çayönü Tepesi'nde ortaya çıarılan zemin ile benzerlik göstermektedir ${ }^{17}$. Akanthou/Tatlısu mimarisinde kireç parçaları ve duvar sıvasina benzeyen işlenmiş, pürüzsüz siva karışımı, kerpiçler arasında harç olarak da kullanılmıştır. Her ne kadar görsel ve tarifsel olarak Çayönü tepesi ile benzerlik gösterse de, Tatlısu sıvalarının gerekli analizleri tamamlanmadan bu konuda varsayım ötesine geçmek mümkün değildir.

15 Rollefson 1990; Garfinkel 1987b.

16 Hauptmann - Yalçın 2001; Kingrey - Vandiver Pricket 1988; Garfinkel 1987a; Gourdin - Kingery, 1975.

17 Gourdin - Kingery 1975, 139.

\section{Önemli Buluntular}

Buluntular arasinda en önemli olan obsidyenlerdir (Res. 9, 10, 11). Kibris'ta rekor denilebilecek bir rakamda - 4000 adetin üzerinde - olan obsidyenin analiz sonuçlarının $^{18}$ Anadolu'yu kaynak olarak göstermesi şaşırtıc1 değildir. Kıbrıs'ta obsidyen buluntular açısından ikinci sırayı 217 adetle Shillourokambos ${ }^{19}$, üçüncü sıray1 ise 32 adetle Kalavassos-Tenta ${ }^{20}$ almaktadir.

Obsidyen kesici aletlerinin tüm katmanlarda bulunmuş olmasından dolayı, sürekliliği ve yoğunluğu açısından Akanthou/Tatlisu'nun Anadolu ile sürekli bağlantı halinde olduğunu rahatlıkla söyleyebiliriz. Form ve teknik olarak Kömürcü-Kaletepe taş aletlerine benzeyen kesici aletlerin hazır bir şekilde adaya getirilme olasıllı̆ı, çekirdek ve yongaların noksanlığından dolayı ağır basmaktadır.

Çakmaktaşı ise adanın iki değişik bölgesinden getirilmiş olabilir. Birinci bölge Akanthou/Tatlisu'ya yakin olan Kantara dağları ${ }^{21}$, ikinci bölge ise tek kaynak olarak bilinen ve çok daha kaliteli karamel renkli çakmaktaşı (Res. 12, 13, 14) ile tanınan Trodos Dağları'dır. Obsidyenin aksine Akanthou/Tatlisu'da işlenen çakmaktaşı, kesici, kazıyıcı ve sık olmamakla birlikte ok ucu ${ }^{22}$ olarak da bulunmuştur. Cilalı baltalar (Res. 15) ve Trodos dağlarında bakır madenleri arasında bulunan pikrolit ${ }^{23}$ taşından yapılmış

18 Analiz sonuçları Şevketoğlu, Herling ve Karsper tarafindan yayına hazırlanmaktadır.

19 Briois et al. 1997, 104

20 Todd 1986, 15.

21 Akanthou/Tatlısu kurtarma kazısı obsidyen ve çakmak taşı uzmanı Lother Herling, kişisel iletişim.

22 Kıbrıs'ta ok uçları ender bulunmaktadır.

23 Pikrolit halk arasında sabun taşı olarak da anılmaktadir. 
keskiler, yine aynı taştan kazıma tekniğiyle yapılmış tarama motifli objeler (Res. 16), kum taşından ögütme aletleri (Res. 17) diğer buluntular arasindadır. Orta Andolu'da Kapadokya Bölgesi'nde bolca bulunan bir kenarı düzleştirilmiş tüf taş1 ise obsidyen ile birlikte adaya getirilmiş olabilir. Bir tarafinın kullanım sonucu düzleşmiş olmasından dolayı bu tüf taşının sıvaların düzleştirilmesi veya kemik aletlerin zımparalanmasinda kullanılmış olmasi olasıdır. Pandantifler (Res. 18) ve üzerinde delik açılmak suretiyle onarım görmüş taş kaplar (Res. 19), blok halinde koyu kırmızı renkte boya parçası, kemikten yapılmış iğne, çuvaldız, bız (Res. 20, 21) ve balık kancaları (Res. 22), türlü deniz kabuklarından boncuklar (Res. 23) ve taş boncuklar diğer Akanthou/Tatlisu eserleri arasında yer almaktadir.

\section{Hayvan Kemikleri}

Akanthou/Tatlisu'da şu ana kadar yapılan çalışmalar sonucunda, Akeramik Dönem hayvanlarının Shillourokambos'taki gibi yarı evcilleştirilmiş bir yapıya sahip olabileceği düşünülmektedir. Özellikle keçi ve koyun cinslerinin daha tam ayrilmadığ1 Muflon türünün varlığ1, çok olmamakla birlikte daha önceleri Erken Tunç Çağında (M.Ö. 2500) adaya getirildiği sanılan sığır; dişi ve erkek arasında büyük bir fizyolojik farklılığın saptandığı geyik; domuz, köpek ve normalden küçük boyda olan tilki gibi hayvanlara ait kemikler bulunmuştur. Akanthou/Tatlisu'ya ilk yerleşenler yanlarında evcilleştirdikleri havanların yanı sira geyik gibi avlayacakları hayvanları da getirmişlerdir. Balık kemikleri arasında, köpek balığ1 ve ton gibi büyük derin su balıklarının yanı sıra, daha küçük kıyı balıkları da mevcuttur. Deniz kaplumbağalarına ait nerdeyse eksiksiz sayılabilecek iskeletlerin Kıbrıs çapında ilk kez bulunması insan ve deniz ilişkilerini farklı bir bilimsel boyutta araştırılmasına olanak sağlayacaktır (Res. 24). 2002 kazı sezonunda yıkılmış bir duvar altında kalan ocaktan çıkardığımız karbonlaşmış 400 adet tohum da bu dönemin bitkileri hakkında bize 1şık tutabilecektir.

\section{Sonuç}

Yüzey araştırmaları ve jeofizik çalışmaları Akanthou/Tatlısu'nun aslinda o döneme göre büyük bir yerleşim yeri olduğunu göstermektedir. Bu büyüklükteki bir yerleşim uzun süre bu bölgede var olabilmiş, zaman ve şartlar değiştikçe aynı bölge içerisinde kayarak yer değiştirmiştir. Alınan tüm sonuçlar bütün bölgede yerleşim yeri olduğunu göstermektedir. Mimari kalıntıların iyi korunmuş olması ve çeşitliliği Kıbrıs'ta bu dönemin ilk mimarı örneklerini daha iyi anlamamızı sağlayacaktır. Hayvan kemiklerinin de aynı şekilde iyi korunmuş olması ve çeşitliliği bu dönemin ekonomisi hakkında ve hatta evcilleştirilme dönemleri ile ilgili bilgiler edinmemize olanak verecektir. Kazılar ilerledikçe yapılar ve kullanımlarıyla ilgili bilgilerimiz daha da somutlaşabilecektir. Gerekli mali kaynaklar bulundukça obsidyen, sıva, kerpiç, balık kemikleri, çakmak taşları, karbonlaşmış organik kalintılar ve diğer malzeme üzerinde gerçekleştirilebilecek analizler, bizi daha kesin sonuçlara ve Kıbrıs-Anadolu ilişkilerinin aydınlanmasına doğru adım adım yaklaştıracaktır.

Günümüzden 10 bin yll öncesini düşünürsek günümüzden daha da zengin bir 
doğa örtüsüne sahip olan Kibris ve özellikle Akanthou/Tatlısu'nun doğal zenginliği, ilk Kıbrislıların yaşam kaynağı olmasında önemli etkendir. Anadolu ile bağlantılarını uzun süre yitirmeyen Akanthou /Tatlısu kültürü, zaman içerisinde Khirokitia gibi obsidyeni unutup yine çakmak taşına mı döndü, yoksa obsidyeni kullanmaya devam eden birçok yerleşim yeri sabırla bizlerin onları keşfetmelerini mi bekliyor? Tipk1 70 y1l sonra Shillourokambos ve Akanthou/Tatlisu'nun yaptıklar1 gibi.

Yrd. Doç. Dr. Müge Şevketoğlu

Doğu Akdeniz Üniversitesi

Arkeoloji ve Sanat Tarihi Bölümü

Gazi Mağusa - Kıbris

\section{Harita ve Resim Listesi}

\section{Harita 1.}

Makalede adı geçen yerleșim yerleri

\section{Resim 1.}

Akanthou/Tatlısu' nun havadan çekilmiş görüntüsü

\section{Resim 2.}

Pikrolit taşından yapılmış kazıma bezeli obje

Resim 3.

Akanthou/Tatlısu kazı alanının genel görünüşü

\section{Resim 4.}

Direk çukurlarının yoğun olduğu bir alanın görünüşü

\section{Resim 5.}

Sivalı tekne

\section{Resim 6.}

Sivalı tekne

\section{Resim 7.}

Sivalı tekne

\section{Resim 8.}

Onbir kat siva

\section{Resim 9.}

Anadolu kaynaklı obsidyen

Resim 10.

Anadolu kaynaklı obsidyen

\section{Resim 11.}

Anadolu kaynaklı obsidyen

Resim 12.

Çakmak tașı alet

Resim 13.

Çakmak taşı alet

Resim 14.

Çakmak taşı alet

Resim 15.

Taş balta

Resim 16.

Kazıma bezeli taş obje

\section{Resim 17.}

Öğütme taş1

\section{Resim 18.}

Pandantif

Resim 19.

Taş kap parçası

Resim 20.

Kemik iğne

\section{Resim 21.}

Kemik iğne

Resim 22.

Kemikten yapılmış balık kancası

Resim 23.

Deniz kabuğundan yapilmış boncuklar

Resim 24.

Deniz kaplumbağası kemikleri 